\title{
10 Lessons Learned from Mexico's Payment for Environmental Services Program
}

\author{
Jennifer Alix-Garcia ${ }^{1}$, Alain de Janvry, ${ }^{2}$ Elisabeth Sadoulet, ${ }^{2}$ and Juan \\ Manuel Torres ${ }^{3}$ with the assistance of Josefina Braña Varela and Maria Zorilla \\ Ramos \\ ${ }^{I}$ Department of Economics, University of San Francisco, San Francisco, CA \\ 94117, Email: jmalixgarcia@usfca.edu; ${ }^{2}$ Department of Agricultural and Re- \\ source Economics, University of California at Berkeley, Berkeley, CA 94720, \\ Emails:alain@are.berkeley.edu and sadoulet@are.berkeley.edu; ${ }^{4}$ División de \\ Economía, Centro de Investigación y Docencia Económicas A.C. (CIDE), Carret- \\ era México-Toluca 3655 Col. Lomas de Santa Fe 01210 México, D.F., Email: \\ juanmanuel.torres@cide.edu
}

\begin{abstract}
This chapter outlines the evolution of Mexico's payments for hydrological services program from its inception through the first two years of the program's implementation. Background information on forests, deforestation, and potential environmental services provide context for a political economy analysis of the path the program traveled through Mexico's legislative and administrative structures. We also analyze the characteristics of the recipients during the first two years, including results from a survey of participants and community case studies. A final section extracts lessons from the Mexican experience, including possible alternative program designs to address some of the problems encountered in its implementation.
\end{abstract}

\subsection{Introduction}

Programs of payments for environmental services (PES) are becoming a popular way of creating, conserving, and restoring natural resources that provide public benefits. These programs encompass a variety of strategies, including payments for the continued existence of a forest, for the planting of native species on fallowed land, or for working-lands projects. Though the term "payments for environmental services" is relatively new, such programs have been in existence for quite some time. The Nature Conservancy pioneered one type of PES strategy, having purchased 116 million acres around the world since 1951 (Nature Conservancy, 2003). In the United States, the water supply of New York City is partially guaranteed by the subsidized conservation efforts of working farmers in the watershed that feeds the metropolis, an effort which began in the 1980s. 
In recent years, such programs have increasingly been introduced by developing countries, with one of the earliest efforts occurring in Costa Rica in 1997, and pilot programs mushrooming throughout Latin America and Asia (World Bank, 2005). In 2002, more than 300 such schemes were inventoried (Mayrand \& Paquin, 2004). Despite the increasing number of such projects, there is a scarcity of rigorous studies analyzing their effectiveness in providing environmental services and their impacts on the people and communities receiving the payments. This chapter intends to partially address this gap by presenting an analysis of the first two years of the Mexican PES program for hydrological services (PSA-H), which began in 2003, where payments are made to individuals and communities as incentives to preserve existing forests. Although the program has not been in place long enough to assess results in terms of forest conserved, sufficient time has passed to extract various lessons from both the political process that led to the program as well as the impact of the payments on recipient communities and, to some extent, on their forest management behavior.

The following pages will outline the evolution of the Mexican PSA-H from the original proposal through the first two years of the program's implementation. ${ }^{1}$ The second section provides background information on forests, deforestation, and potential environmental services in Mexico. Section 10.3 presents a political economy analysis of the path the program traveled through Mexico's legislative and administrative structures. The fourth section focuses on the recipients of the first two years of the program, including a summary of results from a survey of participants and community case studies. Section 10.5 extracts lessons from the Mexican experience, including possible alternative program designs to address some of the problems encountered in its implementation.

\subsection{Deforestation and Environmental Services in Mexico}

According to the National Forest Commission (CONAFOR), forests and areas with natural vegetation (including arid and semi-arid environments) cover $72 \%$ of the Mexican territory (CONAFOR, 2001). Mexico is among the most biologically diverse countries in the world, with first place in reptilian diversity, third in bird, and fourth in mammal diversity. Its plant diversity exceeds that of the United States and Canada combined. The area in temperate and tropical forests (covering over $50 \%$ of the country in 2000) is shown in Fig. 10.1

These biological riches and the hydrological services associated with forests are threatened by deforestation, which has reduced the extension of forests by $50 \%$ over the past five decades. Velásquez et al. (2003) estimate the overall deforestation rate at $1.2 \%$ per year, a rate that, if it continues, would eliminate all forests in

\footnotetext{
${ }^{1}$ Note that this chapter reviews the program through 2005. The Instituto Nacional de Ecología (INE) is currently undertaking an updated review of the program. Also note that since the implementation of the PSA-H, several other federal and local programs to conserve environmental services have begun in Mexico, and the administration has changed.
} 


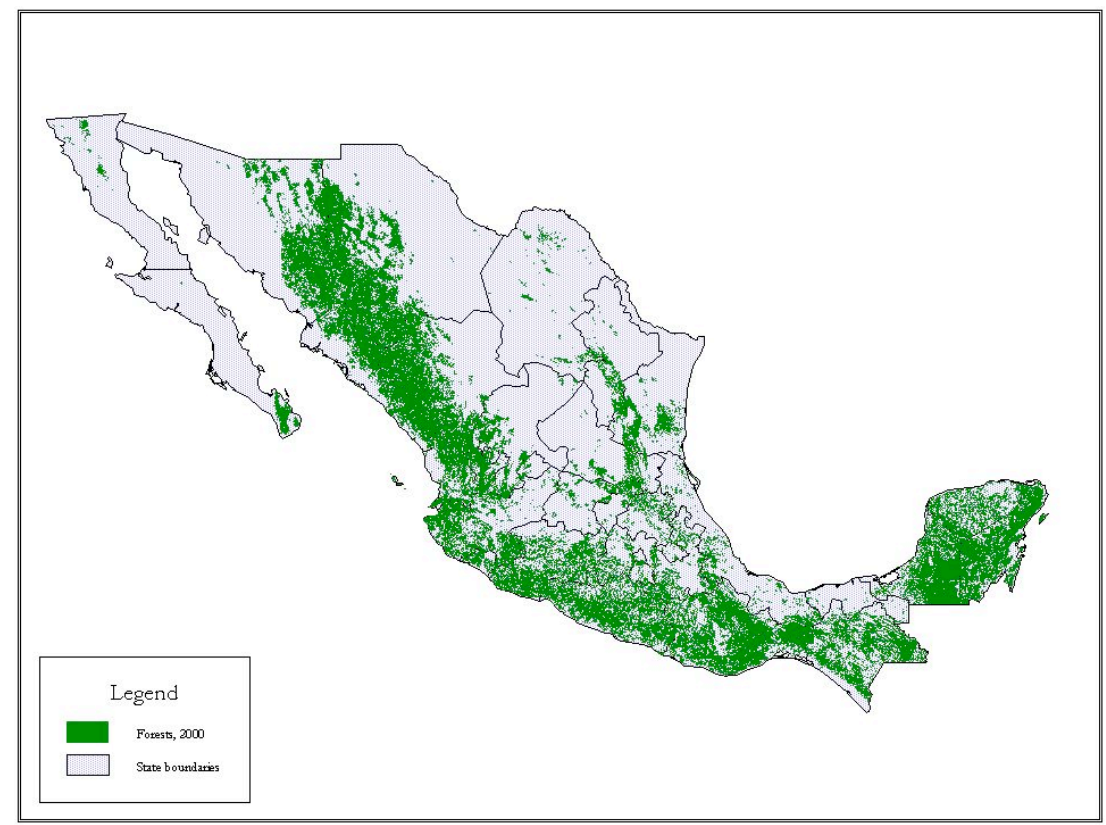

Source: National Forest Inventory 2000, SEMARNAT

Fig. 10.1 Mexican forest cover, 2000

the country within a century. This deforestation is not uniformly distributed across forest types. Table 10.1 shows the distribution of deforestation across forest types between 1994 and 2000. Clearly, deforestation in tropical forests is progressing at a much faster rate, $2.4 \%$ per year, than in temperate forests, $1.2 \%$ per year, and in scrub forests, $0.6 \%$ per year.

About 5\% of Mexico's remaining forest is located in the National System of Protected Areas (SINAP), while private owners control around $15-20 \%$ of the forest. The remainder of the forested land $(75-80 \%)$ is found in the ejidos and comunidades, rural communities resulting from a drawn-out land reform that extended from the end of the 1910 Revolution until the constitutional reform of 1994. In general, these types of communities hold their forests in common and have private parcels for farming.

Where and what are the environmental services provided by Mexican forests? The PSA-H focuses on a service that the forests provide strictly within its national boundaries - the growing scarcity of water. Although the relationship between forest cover and water flows is highly debated, there is clearly a positive effect of forests on water quality, if not always on quantity. For this reason, the original PES program proposal focused on the watersheds defined as overexploited, as 
Table 10.1 Change in Forest Cover by Forest Type from 1993-2000

\begin{tabular}{llll}
\hline Forest Type & $\mathrm{Km}^{2}$ in 1994 & $\mathrm{Km}^{2}$ in 2000 & $\begin{array}{l}\text { Average Annual } \\
\text { Rate of Change }\end{array}$ \\
\hline $\begin{array}{l}\text { Temperate forests } \\
\quad \text { pine, oak, and cloud) }\end{array}$ & 352,969 & 328,471 & -1.2 \\
$\begin{array}{l}\text { Tropical forests } \\
\quad \text { (rainforest and dry tropical) }\end{array}$ & 356,228 & 308,001 & -2.4 \\
Scrub forests & 578,841 & 558,077 & -0.6 \\
All forests & $1,288,038$ & $1,194,549$ & -1.2 \\
\hline
\end{tabular}

Source: Velásquez et al., 2003

well as on cloud forests, which are thought to have a particularly strong relationship with water quantity (García Coll, 2002). According to the National Water Commission, $66 \%$ of the most important aquifers in Mexico are overexploited, with an average extraction $190 \%$ above the replacement rate. It is estimated that $28.7 \%$ of the country's population located in the aquifer area defined as very high or extremely high overexploitation (Muñoz et al., 2005). Around 17,000 hectares of cloud forest, or about 3\% of the total forest, are found in Mexico, all of them in the central and southern zones of the country. As Fig. 10.2 shows, the distribution of these areas is highly regionalized, with major concentrations of overexploited watersheds in the central and northern areas of the country and the bulk of cloud forests in the states of Oaxaca and Chiapas.

With the intent of comparing the total forested area with the area prioritized by the national scheme, Fig. 10.3 shows the distribution of all forests, both tropical and temperate, overlaid with the overexploited aquifers. This figure highlights several important issues. First, it shows that there is little overlap of the forests with the overexploited aquifers, although a forest may help with aquifer recharge without being located within the aquifer itself. It is very important that the forests located in the recharge zone for these aquifers be identified in order to establish which provide potential water services. The cloud forest is clearly located in areas where it is highly unlikely that they are recharging the aquifers of concern.

The forested area is very large, which implies that the potential to provide alternative services with potential international markets, like carbon sequestration and biodiversity, may also be. These types of services may be particularly important for the tropical forests of Southern Mexico, given their lack of overlap with critical watersheds. There are large areas of the country-Baja California, Nuevo Leon, San Luis Potosí, and Zacatecas - which possess very little forest (though they have overexploited aquifers) and that would not benefit from an environmental services program targeted at forest conservation. The water-focus of the PSA-H in Mexico can only justify payments to very specific tracts of forest. However, the large tracts of remaining forest may still house important benefits, including reducing soil erosion, maintaining biodiversity, and improving air quality. 


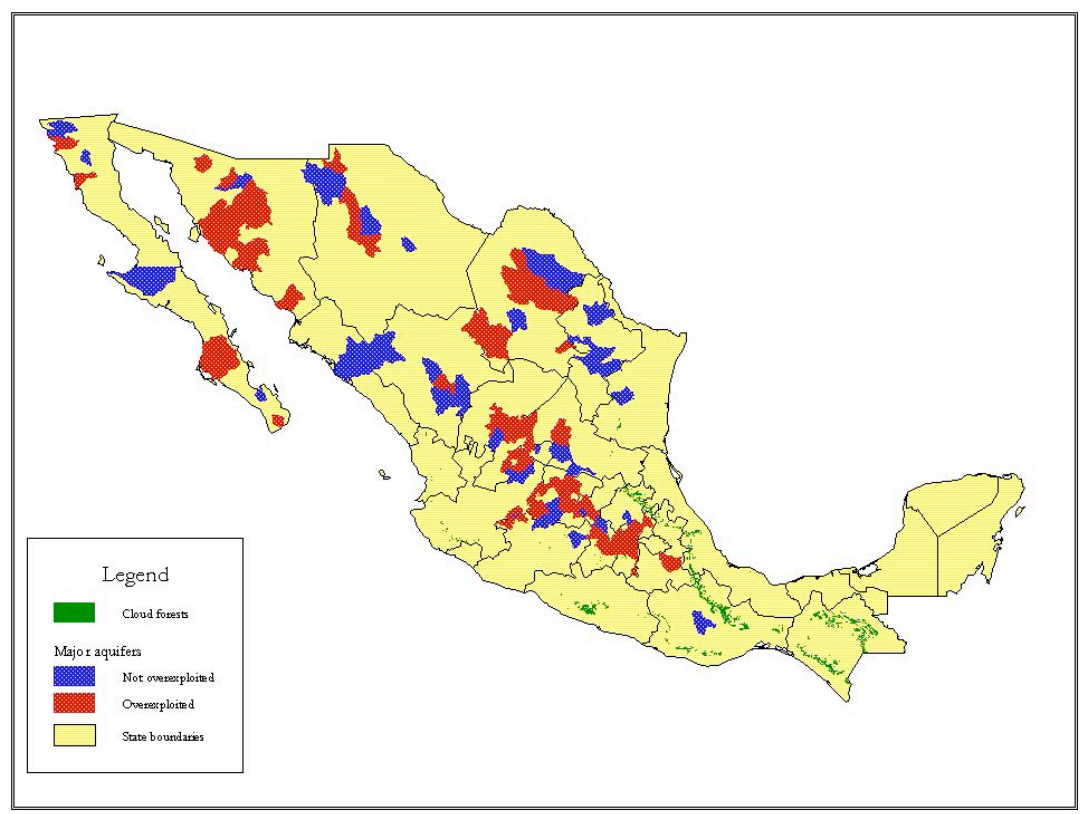

Source: National Institute of Geography and Statistics (INEGI), Mexico

Fig. 10. 2 Major aquifers and cloud forests in Mexico

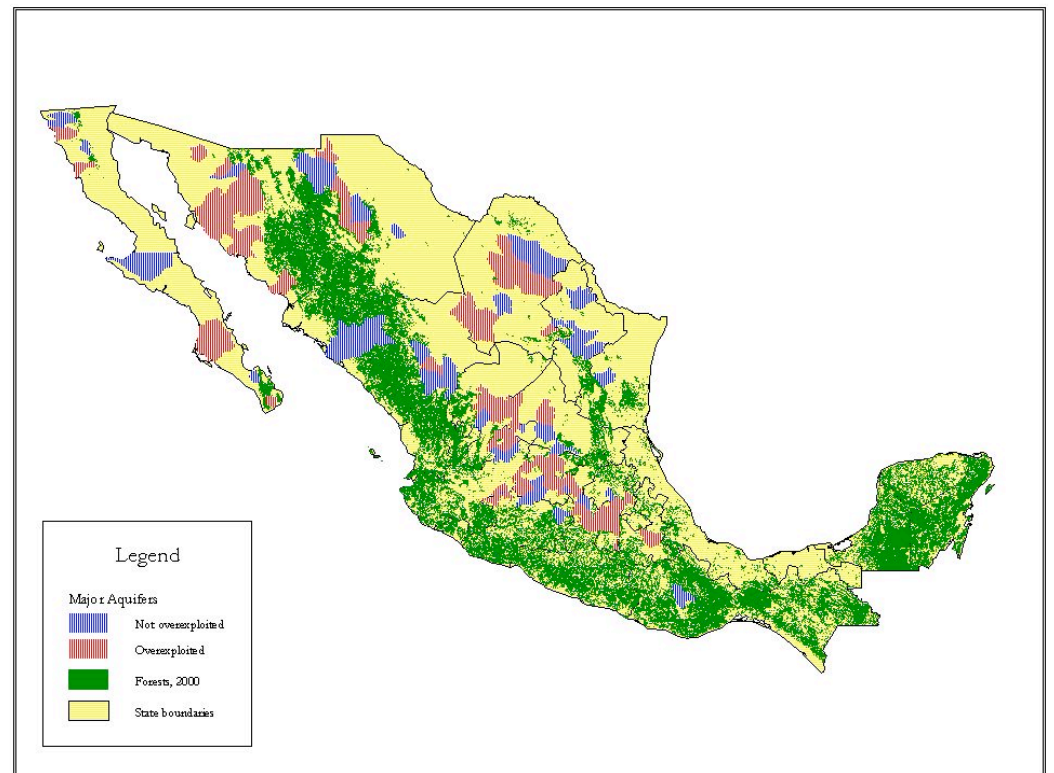

Source: National Institute of Geography, Statistics and Information Systems (INEGI), Mexico.

Fig. 10. 3 Forested areas and overexploited aquifers 


\subsection{The Evolution of Mexico's PES Program for Hydrological Services $^{2}$}

This section details the evolution of the PES program from the beginning of 2000 to the close of the second year of payments in 2005. The initial idea, proposed by the Instituto Nacional de Ecología (INE) together with academics from the Universidad Iberoamericana (UIA), was to target payments towards areas of the country defined as "high" or "very high marginality" according to a municipal marginality indicator based on information from the population census (CONAPO, 2000). The INE hoped to begin with a pilot program administered by an outside institution before launching into a larger, nationwide payment scheme. In October of 2002, the proposed pilot project was intended to last for two years beginning in the spring of 2002 with the following features:

- The pilot would be the responsibility of a Subsecretariat of SEMARNAT, and would include 100 ejidos and an annual payment of \$20 per hectare.

- The project would be focused on water services.

- The beneficiaries would be ejidos and comunidades with forests in "priority watersheds," meaning those that are both overexploited and serving as the main water source for large population centers.

This proposal was presented to a Subsecretariat of SEMARNAT, the directors of which initially allocated $\$ 2$ million over two years beginning in 2002. However, a budget cut to the Secretariat left the program without funding for the following year. Given this lack of support, the Secretary of the Environment presented the project to Felipe Cárdenas, the president of the Comisión Nacional Forestal (CONAFOR), who agreed to take responsibility for it. INE, with technical support from UIA, Centro de Investigación y Docencia Económica (CIDE), and UC Berkeley, proposed to link the financing of the program directly to the services obtained through an additional payment on water use, ideally calculated by watershed. The final objective of the program was to calculate a budget by watershed in order to link the benefits more closely to the costs. Unfortunately, this was impossible to do with the existing data. The lack of data on water services led to the proposal of designating $2.5 \%$ of annual water fees, which for 2002 were around \$20 million, to finance the project. Water fees in Mexico are collected at the municipality level, but because water is officially state property, the fees are sent to the federal government, who then returns them to the municipalities to invest in infrastructure.

The proposal was presented to the Secretariat of Hacienda and Public Credit (SHCP) (similar to the U.S. Treasury Department), which opposed the idea of us-

\footnotetext{
2 This section is a summary of the analysis conducted by Josefina Braña Varela and María Zorilla Ramos. All monetary references are expressed in US dollars unless otherwise noted.
} 
ing water fees to pay for the program, arguing that SHCP had an informal agreement with the municipalities to devolve $100 \%$ of their water fees to be invested in infrastructure projects. In the face of resistance in SHCP, Cárdenas presented the proposal directly to the National Congress, where it was accepted. SHCP, through the Finance Commission, succeeded in converting the $2.5 \%$ levy on water fees into a fixed amount equivalent to $\$ 20$ million per year taken from the water fees collected. This eliminated the possibility for the program to benefit from future increases in water fee revenues. It has been estimated that, had the $2.5 \%$ levy remained in place, the program would have tripled its budget by 2005 .

At this point, several changes occurred in the original proposal. First, the idea of targeting marginalized communities was removed from the discussion. The second important change was that the program would no longer to be targeted toward overexploited watersheds, but instead implemented nationwide. Finally, the pilot project was cancelled as a result of the progress of the political calendar, which made it risky for the agency to run the pilot and then advocate for a national level program.

Soon after, CONAFOR initiated a national tour to promote the program, though at this point it was unclear exactly what the shape of the program would be. This premature promotion was undertaken because the responsible parties were worried that the program would fail due to lack of demand for the budgetary resources, given that the target audience might never have heard of environmental services. Unfortunately, this strategy created a variety of problems. The promotion failed to adequately convey the concept of environmental services, but was very successful in generating false expectations. Because the policy had yet to be well defined, many of the concepts described by the CONAFOR representatives were not incorporated into the final program.

Meanwhile, SHCP classified the new program as a subsidy, which required the submission of "rules of operation" which would have to be debated in a public forum. In April/May 2003, internal negotiations over the rules of operation within CONAFOR resulted in the following changes. Wanting to avoid the technical problem of measuring forest density, the payment schedule changed from three payments ( $\$ 40 /$ ha for high-density cloud forests, $\$ 30$ for medium-density cloud forests and other forests of high density, and $\$ 20$ for forests of medium density) to two ( $\$ 40 /$ ha for cloud forest and $\$ 30$ for others). The liberalization of most of the agricultural products under NAFTA, set for 2003, also affected the program, as an organization composed of various rural opposition groups gained strength. After several weeks of negotiations, President Fox signed an agreement through which he gave the right to a commission of representatives to review and discuss all of government programs having to do with the rural sector. The biggest impact on the program was the inclusion of lands under management for timber harvest, which had previously been excluded from consideration. At the end of the negotiations, the rules were sent to the Federal Commission of Regulation, and published in the Federal Registry on October 3, 2003.

At this date, implementation of the program began under the responsibility of CONAFOR. The fact that the rules of operation were published in October posed 
a substantial problem for CONAFOR, which, due to the rigidity of the governmental fiscal year, had to spend 4 million pesos in less than three months. Normally, funds allocated to federal programs must be spent within the fiscal year, but the managers of the PES program wanted to use the 2003 budget allocation to guarantee payments to participant communities for five consecutive years. Fortunately, the Mexican Forest Fund (FFM) facilitated this process by allowing the set-aside of the remaining $\$ 16$ million from the program's annual budget to cover the next four years. Although the existence of the FFM was a great advantage, allocating even the relatively smaller budget in such a short period of time is a difficult task, and it was complicated by a lack of personnel for program implementation - in October, only three staff members of CONAFOR had been assigned to promote the program and review requests for payments.

Application for the program was very simple-all it required was a two-page form and proof of legal ownership. For ejidos, a document verifying that a general assembly had been called in the participating community and that a vote had taken place was also required. The program contracts gave payments for a specified area of forest within each community's boundaries according to the dual price system of $\$ 40 /$ ha for cloud forest and $\$ 30 /$ ha for other types. In most cases the contract specified that removal of trees from the community's entire forested area (even outside of the area for which payments were being made) constituted a contract violation and subsequent non-payments. Contracts were assessed and renewed on a yearly basis based upon contract compliance the previous year. Monitoring was to be conducted on a random sample of participants using satellite imagery. The criteria for selecting properties were three: 1) Properties with forests with more than $80 \%$ density (i.e., hectares with more than $80 \%$ tree cover), 2 ) located in overexploited aquifers, and 3) with nearby population centers greater than 5,000 inhabitants.

CONAFOR hired supplemental workers to assist in the promotion of applications and the selection of recipients. Unfortunately, by the time the hiring and training process was over, there was only one month left for these activities. As a result, the promotion of the program was only done to CONAFOR's traditional constituency-ejidos and private landowners with wood extraction projects supported by its other programs.

CONAFOR received many more demands than it could finance. With only three employees to review, catalogue, and evaluate 900 proposals, several changes were made in order to expedite the process. First, a combination of misinterpretation of the rules and the fact that there was only one geographical technician to analyze the satellite images resulted in the elimination of the criterion of forest density in favor of forest coverage, meaning that only properties that were more than $80 \%$ covered with forest were selected. This resulted in the selection of much larger properties, and with lower population density and probably a lower probability of deforestation than if the $80 \%$ forest density criterion had been used.

CONAFOR had considered monitoring the program through high-resolution satellite images. However, insufficient time and staff meant that satellite images of potential properties were not purchased, with the result that properties located 
in regions where images had not been purchased were not allowed in the program. In addition, if the properties were not already georeferenced, they could not receive payments since placing them on a satellite image would be impossible. Finally, in the communities with forest extraction activities, it was often impossible to determine if the area chosen for environmental payments overlapped with area earmarked for tree harvests.

At the beginning of 2004, two important selection criteria were added as a result of an internal shift of responsibilities within CONAFOR. A piece of land could be in a National Protected Area or in a "Priority Mountain" and receive the same priority as a property in an overexploited watershed. The Priority Mountain program was also administered by CONAFOR, and focuses on protection water production, carbon capture, and biodiversity in 60 mountains throughout the country. Table 10.2 summarizes the changes in the targeting criteria from the original proposal to the program's 2003 implementation.

In 2004 CONAFOR again received applications far in excess of what it could finance. By this time, however, a shift of management within CONAFOR had resulted in a point system approach: payments were allocated by giving a point for each of the criteria listed in the rules of operation and contracts awarded to those properties with the highest point values.

Table 10.2 Changes in the Targeting Strategy

\begin{tabular}{ll}
\hline Original Targeting Rules & Final Targeting Rules \\
(SEMARNAT/INE) & (SEMARNAT/CONAFOR) \\
\hline
\end{tabular}

- Pilot program with an experimental design - Nationwide program

- Beneficiaries ejidos and comunidades lo- $\quad-\quad$ Rules of operation cated in priority watersheds

- Establishment of a trust fund

- Overexploited

- Beneficiaries augmented to include private

- $\quad$ Serving large populations owners

- Other selection criteria:

- Added selection criteria

- Forest cover

- Clear property rights

- Ecosystem type

- Marginalization

- Priority given to forest with high deforestation risk

- $\quad$ Priority mountains

- Availability of satellite image

- Protected areas

- Subtracted selection criteria

- Marginalization

- Deforestation risk 


\subsection{Results of Implementation, 2003-2004}

\subsubsection{Summary Statistics for Participating Communities}

This section describes the recipients of the initial payments made by the program. The data used to characterize the participants come from an evaluation of the program conducted by the Colegio de Posgraduados (COLPOS, 2004) and a survey conducted by INE (INE, 2004). The COLSPOS survey was comprised of over 300 randomly selected participants (common property and private owners), while the INE survey covered 27 participant ejidos selected to reflect the mean characteristics of the ejidos participating in the PES program in 2003. Except where otherwise noted, the statistics presented come from the INE survey.

Applications for the program were received from 25 states, but only 15 actually received PES contracts, with nearly 127,000 hectares enrolled. Table 10.3 shows the distribution of payments by state. A few states-Oaxaca, Durango, and Veracruz - got a large share of the budget (43\%). The states with the smallest number of hectares enrolled were the Distrito Federal, Nuevo León, Baja California Sur, and Nayarit.

Table 10. 3 Distribution of PES Contracts by State, 2003

\begin{tabular}{|c|c|c|c|c|c|}
\hline State & $\begin{array}{l}\text { Number of } \\
\text { Contracts }\end{array}$ & $\begin{array}{l}\text { Hectares } \\
\text { Enrolled }^{\dagger}\end{array}$ & $\begin{array}{l}\text { Hectares } \\
\text { Forested }^{\dagger \dagger}\end{array}$ & $\begin{array}{l}\text { Percentage } \\
\text { Enrolled }\end{array}$ & Payments $^{\dagger \dagger}$ \\
\hline Baja California Sur & 2 & 2,231 & 442,874 & 0.50 & 63,749 \\
\hline Coahuila & 29 & 7,188 & 514,771 & 1.40 & 205,368 \\
\hline Chihuahua & 8 & 11,279 & $7,702,586$ & 0.15 & 322,269 \\
\hline Distrito Federal & 4 & 5,058 & 38,301 & 13.21 & 144,507 \\
\hline Durango & 16 & 15,224 & $5,870,668$ & 0.26 & 434,959 \\
\hline Estado de México & 2 & 709 & 740,205 & 0.10 & 20,271 \\
\hline Jalisco & 24 & 11,801 & $4,407,937$ & 0.27 & 337,175 \\
\hline Michoacán & 10 & 8,633 & $3,510,806$ & 0.25 & 254,317 \\
\hline Nayarit & 9 & 3,222 & $1,731,879$ & 0.19 & 96,721 \\
\hline Nuevo León & 1 & 1,450 & 571,327 & 0.25 & 41,424 \\
\hline Oaxaca & 20 & 28,469 & $6,392,049$ & 0.45 & 813,396 \\
\hline Puebla & 19 & 5,655 & $1,599,605$ & 0.35 & 168,641 \\
\hline Querétaro & 45 & 4,664 & 419,098 & 1.11 & 143,792 \\
\hline San Luis Potosí & 7 & 9,874 & 857,912 & 1.15 & 282,121 \\
\hline Veracruz & 75 & 11,361 & $1,135,089$ & 1.00 & 328,434 \\
\hline TOTAL & 271 & 126,818 & $35,935,107$ & 0.35 & $3,657,143$ \\
\hline
\end{tabular}

${ }^{\dagger}$ CONAFOR 2004 www.conafor.gob.mx

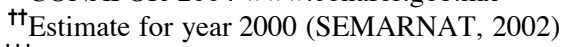

${ }^{\mathrm{tt \dagger}}$ US dollars. Data from CONAFOR 2004 www.conafor.gob.mx 
For the first year of operation, ejidos and comunidades accounted for $47 \%$ of the contracts and for $93 \%$ of the area contracted. Table 10.4 shows the main characteristics of participating communities. The average size of participant ejidos was 3,961 hectares. The mean number of hectares enrolled in the program is 466 , with $2.8 \%$ of the total hectares in the sample being cloud forests. On average, $75 \%$ of the land in participating ejidos is considered common property. Out of the sample of 23 common properties receiving payments, 15 (65\%) had experienced deforestation over the 1994-2000 period. The average yearly rate of forest loss amongst those with positive deforestation was $1.5 \%$. $63 \%$ of the participants harvest wood for sale, and within these ejidos, $74 \%$ have reported illegal logging in their properties. In some of these ejidos, the legal harvest volumes exceed 32,000 cubic meters, far beyond the national average of 4,546 cubic meters a year.

Table 10.5 details the distribution of PES hectares according to watershed, where the population is all the participants in the program. According to this information, the payments have not been going to areas where the aquifers are overexploited. Essentially no hectares under PES are forests in aquifers qualifying as extremely or strongly overexploited. 78 and $85 \%$ of the PES hectares, in 2003 and 2004 , respectively, are in aquifers that are not over-exploited, with the remainder of the hectares in aquifers that qualify as moderately overexploited. Just because a property is not directly on top of an aquifer, however, does not mean that it is not in the recharge zone of that aquifer.

Table 10.4 Physical Characteristics of Participating Ejidos

\begin{tabular}{ll}
\hline Characteristics & Estimate \\
\hline Average size of forested area, in hectares & 3,961 \\
Average hectares enrolled in the program & 466 \\
Total hectares of cloud forest in the sample & 1,830 \\
Total hectares of temperate forest in the sample & 55,280 \\
Total hectares enrolled in sample & 12,680 \\
Percentage of participants with cloud forest (from total) & 2.9 \\
Average annual forest loss in hectares, 1994-2000 & 38 \\
Percentage of participants harvesting wood for sale & 63
\end{tabular}

Source: Own estimates with data from INE (INE, 2004)

Table 10.5 Distribution of Payment Recipients by Aquifer Type, 2003 and 2004

\begin{tabular}{lllll}
\hline & Total & Population & \multicolumn{2}{l}{ sHectares in Hectares in } \\
Aquifer Type & Area & Living in & PES, 2003 & PES, 2004 \\
$(\%)$ & Area $(\%)$ & $(\%)$ & 0.00 \\
\hline Extremely overexploited $(+100 \% \mathrm{a}+800 \%)$ & 0.05 & 9.2 & 0.02 & 0.00 \\
Strongly overexploited (+50\% a +100\%) & 0.04 & 19.5 & 0.00 & 9.6 \\
Moderately overexploited (+5\% a +50\%) & 18.6 & 14.5 & 13.3 & 0.00 \\
In equilibrium (- 5\% a +5\%) & 2.9 & 11.3 & 0.01 & 85.0 \\
Not overexploited $(<-5 \%)$ & 65.1 & 45.4 & 78.7 & 5.3 \\
No data & 13.4 & 0.1 & 8.0 & 100 \\
TOTAL & 100 & 100 & 100 &
\end{tabular}

Source: Muñoz et al. (2005) 
Table 10.6 shows the distribution of PES hectares according to forest type. Recall that cloud forests are given a slightly higher payment per hectare under the current scheme, with the hope that a proportionately higher number of cloud forest hectares be enrolled. Again, these results are based on a census of the payment recipients. The effort to enroll a larger proportion of cloud forests was successful; in 2003, 6.8\% of the enrolled hectares were cloud forests and, in 2004, 16.3\%, relative to the overall percentage of 3.4 and the eligible area of $6.6 \%$. The temperate forest categories of pine, oak, and fir are over-represented as a group, both relative to the eligible areas and the national distribution. This may be because there are more commercial forests in these ecosystems, and the owners of these forests are likely to have a closer relationship with CONAFOR through other programs administered by the Commission. It is impossible to tell whether this bias results from greater promotional efforts by CONAFOR with these types of forest holders or is simply the result of self-selection.

In order to predict how effective the payments might be in reducing deforestation, it is interesting to consider the distribution of the payments according to predicted deforestation risk. Table 10.7 shows the distribution of forest area among participants according to deforestation risk estimates, where risk is determined by exogenous community characteristics. It can be observed that most of the participant forests have low and very low deforestation risk indices, suggesting that they would have been conserved even in the absence of the program.

Table 10.6 Comparison of Forest Types Enrolled in PES, 2003 and 2004

\begin{tabular}{|c|c|c|c|c|}
\hline Forest Type & $\begin{array}{l}\text { Distribution } \\
\text { at the } \\
\text { National } \\
\text { Level }(\%)\end{array}$ & $\begin{array}{l}\text { Hectares } \\
\text { Enrolled in } \\
\text { PES, } 2003 \\
(\%)\end{array}$ & $\begin{array}{l}\text { Hectares } \\
\text { Enrolled in } \\
\text { PES, } 2004 \\
(\%)\end{array}$ & $\begin{array}{l}\text { "Eligible" } \\
\text { Area }^{\dagger} \\
\text { CONAFOR } \\
2004(\%)\end{array}$ \\
\hline Pine and oak-pine forests & 37.8 & 60.1 & 43.9 & 46.4 \\
\hline Oak-fir forests & 23.0 & 17.2 & 24.9 & 18.0 \\
\hline Cloud forests & 3.4 & 6.8 & 16.3 & 6.6 \\
\hline Low tropical forests & 25.0 & 3.0 & 4.9 & 2.4 \\
\hline Medium and high tropical forests & 10.8 & 12.9 & 10.4 & 26.6 \\
\hline TOTAL & 100 & 100 & 100 & 100 \\
\hline
\end{tabular}

Source: Muñoz et al., 2005

${ }^{\dagger}$ In 2004, CONAFOR used three criteria to define eligibility: overexploited aquifers, priority mountains, and protected areas.

Table 10.7 Distribution of Deforestation Risk in Participant Communities

\begin{tabular}{|c|c|c|c|c|c|}
\hline Deforestation Risk Index & \multicolumn{2}{|c|}{2003 Recipients } & \multicolumn{2}{|c|}{2003 Recipients } & National \\
\hline & $(\%)$ & Hectares & $(\%)$ & Hectares & $(\%)$ \\
\hline Very high & 3.6 & 5,922 & 10.9 & 18,550 & 20 \\
\hline High & 6.7 & 11,034 & 16.8 & 28,529 & 20 \\
\hline Medium & 17.3 & 28,446 & 20.5 & 34,953 & 20 \\
\hline Low & 30.4 & 50,046 & 29.9 & 50,940 & 20 \\
\hline Very low & 41.9 & 68,815 & 21.8 & 37,133 & 20 \\
\hline Total & 100 & 164,263 & 100 & 170,105 & 100 \\
\hline
\end{tabular}

Source: Muñoz et al. (2005) 
Table 10.8 describes the distribution of PES hectares according to the level of marginalization of the participating communities. The definition of marginal is given by Mexico's National Population Council (CONAPO, 2000) and is based upon a combination of nine indicators encompassing literacy, education, employment, and quality of dwelling. Interestingly, even though marginality was removed from the program as a selection criterion, the majority of the enrolled hectares $-71.9 \%$ in 2003 and $82.9 \%$ in 2004 - are located in areas with high or very high marginality. It is important to emphasis that the correspondence between payments and poverty is purely coincidental, reflecting the fact that $80 \%$ of the forest in Mexico is held by ejidos and comunidades, and that within this group, $86.3 \%$ of the forest is located in communities with high or very high marginality. Some bias does appear to exist towards including areas of high, rather than very high, marginality. One explanation for this is that the former communities are less likely to have commercial forests (and hence contact with CONAFOR), and are probably more remote and therefore difficult to reach.

It is also interesting to consider how payments received were distributed within communities. The use of the 2003 payments varied from distributing 100\% equally between all members to investing all the money into public goods for the community, with many intermediate cases where the allocation included a combination of direct distribution of payments, payment for guarding the forest and fire prevention, and investment in local public goods. The survey shows that $18 \%$ of the ejidos decided to distribute all payments directly among ejido members, $22 \%$ invested the entirety in forest activities related to conservation, $18 \%$ allocated the full amount to public goods not related to forestry, while the remaining $42 \%$ adopted a combination of the three strategies.

In $87 \%$ of the communities surveyed, participants declared that they had respected the contract, while $26 \%$ stated that they had deforested over the past two years. Note that deforestation is not necessarily a breach of contract, given that some contracts are not specified to be inclusive of all the forested area. In most cases, the activities implemented as a result of the program included increasing

Table 10.8 Marginalization and PES

\begin{tabular}{|c|c|c|c|c|c|c|}
\hline \multirow[t]{2}{*}{ Level of Marginalization } & \multicolumn{2}{|l|}{ PES 2003} & \multicolumn{2}{|l|}{ PES 2004} & \multirow{2}{*}{$\begin{array}{l}\text { Proportion in } \\
\text { Ejidos with > } \\
100 \text { Hectares } \\
\text { of Forests } \\
(\%)\end{array}$} & \multirow{2}{*}{$\begin{array}{l}\text { National } \\
\text { Distribution } \\
\text { across For- } \\
\text { ests } \\
(\%)\end{array}$} \\
\hline & Hectares & $(\%)$ & Hectares & $(\%)$ & & \\
\hline Very high & 41,282 & 25.0 & 36,567 & 21.5 & 69.1 & 31.2 \\
\hline High & 77,339 & 46.9 & 104,362 & 61.4 & 17.2 & 16.3 \\
\hline Medium & 29,924 & 18.1 & 13,521 & 7.9 & 8.6 & 22.2 \\
\hline Low & 13,018 & 7.9 & 9,741 & 5.7 & 3.3 & 10.1 \\
\hline Very low & 3,386 & 2.1 & 5,839 & 3.4 & 1.8 & 20.3 \\
\hline Total & 164,948 & 100 & 170,030 & 100 & 100 & 100 \\
\hline
\end{tabular}

Source: Muñoz et al. (2005) and own estimates with data from CONAPO (2000). 
the surveillance of forestlands and revision of rules regarding the extraction of forest resources. In no cases were new activities introduced as a result of the program. Payments had not been withheld from any of the survey participants, suggesting that either compliance is very good or the monitoring system is not very effective. Monitoring of the contract after the first year of operation was performed randomly in 28 ejidos (22\%) in November 2004. All monitored ejidos met contract requirements. The annual cost of operation and monitoring for the first year of operation was estimated at $\$ 714,285$, yielding an average cost of $\$ 5.6$ per hectare absorbed by CONAFOR. Compared to payments of $\$ 30 /$ hectare, this indicates that administrative costs represent $19 \%$ of the PES budget. In addition, there is an annual evaluation of program objectives, processes and expenses made by an external institution. For the first year, this evaluation amounted to \$98,214.

\subsubsection{Case Studies}

\subsubsection{Basic Findings}

In the winter of 2004-05, case studies of 11 communities receiving the pilot payments were undertaken in the states of Michoacan, Puebla, Veracruz, Durango, Chihuahua, and Coahuila. Given that the majority of the forest in the program is from ejidos and comunidades, all case studies were conducted in these types of properties. This section summarizes the overall findings. ${ }^{3}$ The intention of these studies was to detail the experience of the recipient communities in order to understand how they were managing their forests before the PES program, if this behavior had changed with the payments, and if the payments had affected the internal dynamics of the communities.

The studies cover a variety of communities with varying membership and size in different institutional situations. The membership size ranges from 40 to 225 , while the area ranges from 493 to over 10,000 hectares. The forest area enrolled in the PES program in each community varies from 73 to 1,400 hectares. Four ejidos included areas of forest that are organized for wood extraction under the permit system. Three communities were located in the Biosphere Reserve las Tuxtlas, which constitutes a unique institutional context within Mexico, as there are rules specifying limitations on certain extractive uses.

With regards to our first question, we found that 5 of the 11 ejidos had deforested in the period prior to receiving payments. As was suggested by the statistics of the previous section, the case studies imply that a significant proportion of the budget may be being paid to people who were not planning to cut down the forest in the first place. All of the ejidos interviewed were already engaged in some form of conservation activity before implementation of the program. This sug-

\footnotetext{
${ }^{3}$ The studies were conducted by Adán Martínez Cruz, Josefina Braña Varela, and Jaime Sainz Santamaría.
} 
gests a selection bias in the program design - it is highly likely that communities with some experience in conservation would volunteer to participate in a program requiring conservation activities. The three forestry ejidos of the Northern states all participate in conservation activities, which are actually part of their forest management plan.

In the three Northern forestry ejidos, the main use of the forest is extractive forestry under a management plan designed by a forest technician from outside the community. These communities exhibited a high percentage of forest loss (12.4, 12.1 , and $6.6 \%$ ) over the period from 1994 to 2000 . However, their extractive activities began after 1994, and the ejidos practice a rotation style of forestry that involves harvesting a parcel and then allowing it to rest for 10 years. It is unclear whether the large initial forest loss came from the first phase of the forestry process or whether it is the result of an unsustainable deforestation path. In addition to the extraction itself, there is some pressure on these forests originating in the expansion of the urban area of these communities, from subsistence agriculture, forest fires, and pest infestation. In one particular case, the forest loss is mainly the result of a forest fire that occurred in 1998. Much of the area that is recovering from the fire is currently being included in the program. The other activity taking place within the forest is the grazing of a small cattle herd whose owners reside within the ejido. This community used the PES as a way to induce the cattle owners to move the small herd away from the recuperating land.

In most cases, communities stated that they had intensified their conservation efforts by increasing their frequency as a result of the program. These facts were not corroborated by outside sources, and in some instances the case study teams perceived that community members had trouble locating firebreaks and forest roads that they claimed to be maintaining. The forestry communities seem to see the program as a way of subsidizing their forestry project-the hectares of land integrated in the program are in fact hectare, which are part of a 10-year rotation and happen to be in fallow at the moment. In one case, however, the PES land is located in what is considered a sensitive area for water conservation, and it has therefore been fenced in and is monitored to ensure that no one enters into the area. This ejido does not intend to put this particular piece of land back into production. The results of this section suggest that significant behavior change induced by forest conservation payments is unlikely since many communities were already preserving the forest.

Another situation where payments were used to provide a sustained incentive for mandated conservation activities was found in the Biosphere Reserve, where communities are forbidden to continue extractive projects in their forests. The provision of payments to these communities could be seen as replacing the command-and-control approach, which is difficult to enforce and seen as unfair by forest owners.

It is also important to note that, with the exception of the two cases in Northern Mexico, the communities received no technical assistance in the design of their PES implementation schemes, and in fact were not even aware of the contractual requirements of such a scheme. It is unreasonable to expect communities without 
technical assistance or experience in forest management to be able to create an effective management plan.

It is possible that in many cases, the amount of money received by the communities was not sufficient to induce any sort of behavioral change. The total annual payments by community vary widely, from $\$ 2,200$ up to nearly $\$ 45,000$, as do the ways in which communities decided to divide up this money. In over half of the cases, the majority of the allocation was divided up and given to individual ejido members. Per capita payments, under the assumption that the allocation was equally divided between all ejido members, vary from $\$ 60$ per member to $\$ 1,100$. Given that GDP per capita in Mexico in 2003 was around $\$ 6,000$, these amounts very from totally insignificant to substantial, with the majority falling on the low end (CIA, 2005).

In only one case was $100 \%$ of the money distributed equally among all ejido members. In all of the other communities, a percentage ranging from 3 to 100 was invested in some kind of public good, where public goods in this case include equipment used to monitor the forest commons (radios, trucks), infrastructure like school classrooms, and road maintenance. There are several reasons why ejidos might choose to invest the majority of the payments in public goods. First, it is possible that there are returns to scale in these investments. That is, giving a transfer of $\$ 75$ per year may not be as valuable to a family as using the same money to build new classrooms for the school where the family sends its children to study. Second, these goods can be enjoyed by non-members of the community who would not normally have rights to cash transfers from ejido funds. Finally, there is evidence of sharing norms present in the ejidos and comunidades of Mexico, and it may simply be that it is preferable for them to distribute this money in a more egalitarian fashion through investment in public goods. One very interesting development in two of the communities interviewed was the proposal to form local microbanks using the PES money as seed capital.

Although in most cases there was no obvious change in the social dynamics within the ejido, in two cases there was a shift in the relative power of different groups within the communities. In both of these cases, forests were located in what the community had defined as parceled areas (rather than common property) within the ejido boundaries. The outcome of this division was that it gave the owners of these forests the ability to make a credible threat to cut them down if their demands were not met. In the first case, the forest holders were receiving payments but requested they be adjusted to reflect the proportion of forest located in their parcels. This proposal was voted upon and accepted by the assembly and will be put into effect in the next round of payments. In the second, the members with forested parcels were not receiving payments and threatened to cut down their forest if they did not receive some proportional compensation in the next round. An additional result of the program in this community was that participation in conservation activities was reduced. This phenomenon was a direct consequence of the way in which the payments were divided up-only those with rights to the commons received them. It is somewhat unusual that only a small part of the membership of an ejido would have rights to the commons. In this case, the 
decision had been made to give commons rights to those with very small private parcels. Prior to the program, all ejido members had participated in forest surveillance and maintenance. Once the payments were received, non-recipients withdrew from these activities.

In two happy cases, we observed that the allocation of the PES funds resulted in an increased environmental awareness and participation of a greater number of community members in conservation activities. Although the authors of the cases noted that one of these communities clearly had higher levels of social capital than some of the other participants, it also received a much larger payment, both in total and on a per capita basis. In addition, the payments were not divided up equally among members, but rather were distributed according to the level of participation in the activities they deemed necessary to fulfill the program requirements.

\subsubsection{Other Case Study Findings}

\section{Misunderstanding of the Program}

One of the most discouraging findings was that in none of the communities visited were the objectives and rules of the program clear to the members. This was not surprising given the time restrictions on program promotion. Interestingly, the majority of ejidos were able to identify the cities that benefited from the hydrological services provided by conservation of their forests, but none of them realized that the payments they were receiving were meant to be in compensation for these services. In several cases, interviewees stated that they thought the payments were a poverty-alleviation mechanism somehow linked with forests.

\section{Corruption}

Another unsettling finding was that, in at least one case, the intermediary responsible for helping the communities fill out the paperwork for the program covered a "fee" equivalent to some percentage of the final payment.

\section{Slippage}

The term slippage, coined by $\mathrm{Wu}$ (2000), refers to the bringing into production of other land as a result of removing land from production and putting it into a conservation program. Although in most of our cases this was not a risk, given that the forest integrated into the program was not slated for any use by the ejidos in the first place, we did observe slippage in two cases in the ejidos in Northern Mexico. In one case, cattle were removed from the forest to be entered into the program and placed in another area not previously used for grazing, although it is 
not clear if this area was forested or not and whether it was located in the commons or in a private parcel. In the second instance, the community put in the program forested land that they had programmed for harvest, and instead harvested another area of the forest.

Another phenomenon which is related to slippage is the use of the program as a way of receiving payments for land which the ejido intends to use productively in the future. We saw this in the forestry ejidos that decided to enroll into the program hectares that are part of their 10-year harvesting rotation. With permission of the forestry authorities, these ejidos then modified their forestry plan to put different hectares into production.

\subsection{Learning from the Mexican Experience}

\subsubsection{Lessons in Political Economy}

There are multiple lessons to be derived from the administrative and political processes to which the Mexican PES program was subjected. Many of the forces that modified the program's objectives were not foreseeable and could not have been circumvented. In this section we focus on aspects of policy design and implementation, which could provide useful guidance for the continuation of Mexico's program and for programs in other countries.

\subsubsection{Program Design and Promotion}

The first important lesson for policy designers is the need to establish clear objectives and criteria for the program before promotional activities take place. The nationwide tour caused confusion regarding the purpose, rules, and financial mechanisms of the program. This resulted in bad blood at the local government level in places and an overabundance of unqualified applications, which merely exacerbated CONAFOR's staffing and time constraints. Clearly defined criteria and objectives could also have helped minimize the problems that occurred during the implementation phase and increase transparency of the program. A welldefined program may even have facilitated the early stage negotiations with Hacienda and improved the quality of the "rules of operation." Finally, clear objectives would have aided in the promotion of the program and the understanding of it among the participants.

Participants in the early phases of the Mexican program emphasize the importance of forming an advisory group of both national and international experts to aid in the policy design process. The combination of expertise from outside the country and experts aware of the realities of implementing programs in Mexico 
expedited the design of the program and allowed recommendations to be made quickly and effectively. Whether or not these recommendations get implemented depends very much on the relationship between the policymakers and the intermediate provider or implementing agencies, which leads us to the next point.

\subsubsection{Choice of Implementing Agency}

In the Mexican case, the choice of CONAFOR as an intermediate service provider had very important impacts on both payment structure and targeting. Many of these changes resulted from the fact that CONAFOR's traditional program objectives and constituency-owners of commercial forests-differed from the program's objectives and target population. It was easier for CONAFOR to communicate and negotiate with this group since they had already established relationships through other programs. As we saw in the summary statistics section, the result of this relationship was that $63 \%$ of participating ejidos extract wood for sale; $79 \%$ of the PES hectares in 2003 and $85 \%$ in 2004 were in watersheds that were categorized as "not overexploited."

An additional objective that influenced CONAFOR's implementation of the program in later rounds was the desire to support another of its programs - the Priority Mountains Programs. This program's budget shared the PES objective of preserving water production through forest conservation. These two features made it logical to funnel the PES funds towards these mountains, with the useful result of reducing administrative costs by concentrating the two programs in the same geographical areas. $46 \%$ of the 527,515 hectares enrolled in the PES program in 2004 were located in areas within the Priority Mountains program.

It is extremely important to reiterate that CONAFOR brought to the program two essential benefits: the desire to implement the program and the political clout necessary to obtain a budget for it from Congress. Without CONAFOR, it is very likely that Hacienda would have blocked the allocation of money to a PES program indefinitely. The trade-off here is an important one: one chooses an intermediate service provider whose incentives are partially misaligned with the objectives of the policymakers in exchange for obtaining a budget for the program.

\subsubsection{PES Contracts}

The contracts between the intermediate provider, CONAFOR, and the final service providers, the ejidos, must give the forest communities sufficient incentives to cease their extractive activities in favor of conservation. This requires that payments be high enough to compensate for the loss of forest extraction, agriculture, or cattle grazing and that there be sufficient monitoring and enforcement of program rules. The case studies and the statistics regarding deforestation risk show us that much of the forest currently under contract is likely to have a very low opportunity cost - that is to say, one would not have to pay very much in order to 
compensate for the loss of income from activities currently taking place in these forests. In this sense, the magnitude of the payments appears to be high enough given the forests that are enrolled in the program - whether or not these payments would be high enough to preserve all of the water services at risk of being lost is another issue, and one we will return to in the discussion of targeting.

One way to eliminate the guesswork in the magnitude of payment design is to use an auction process to induce potential participants to reveal the minimum payment, which they would accept in exchange for conservation of their forest. Although we have yet to hear of such an approach being applied in an environmental services scheme, the Conservation Reserve Program in the United States did take a step in this direction by allowing potential participants to place a bid that can affect the probability that they will be included in the program. Another option would be to conduct rigorous contingent valuation studies in areas targeted by the program.

One feature of the contracts, which is important and easily replicable in other situations, is that contracts should be made over the entire forested area. In order to avoid the movement of productive activities from PES hectares to other previously unused forests within the ejidos, it is very important that contracts for payments specified that there should be no change in the entire forested area. This does not imply that payments should be given for all of the hectares of forest within the ejido, but rather that the contracts should eliminate the possibility that deforestation be reallocated from one spot in the community to another. Agreements can allow for some pre-specified amount of forest conversion. Were the program not to have followed this strategy, an ejido receiving payments for 10 out of 100 forested hectares within its boundaries might then deforest with impunity the remaining 90 hectares not included in the program. Obviously the choice of which hectares to pay for should not be arbitrary. The logical option is to pay for those hectares of land, which are at risk of being deforested. Such an approach is described in more detail in section 10.5.3.

The timing of the payments of the PSA-H is sensible and easy to replicate. Payments are given at the end of each period, after verification of the conserved forest cover. In effect, the payments, since they are made on a yearly basis, are a rental contract for the environmental services provided by the forest over the year. This arrangement is logical since it is much easier to withhold a payment than to request its return, and there is a clear moral hazard problem with paying before the receipt of a service. As a result of the need to spend the initial budget quickly, the first year's payments were given for forest conserved in the previous year. This is not a method we would recommend for other programs, although it was politically expedient.

An important part of being able to give or withhold payments relies on having an objective measure of change in forest cover. Here we find another positive lesson from the Mexican strategy. The monitoring scheme consists in choosing communities at random and assessing the quality of their forest cover using satellite images, which are both transparent and difficult to manipulate. 


\subsubsection{Within Community Contracts}

Mexico is unique in having most of its forest held under common property. However, many other countries also have substantial tracts of forest under similar institutional arrangements, and it is important to mention lessons learned within this context. The case studies indicate that members of most communities did not know why they were receiving the payments. This could be quite detrimental to achieving forest conservation. This is because the payments must provide an incentive for individuals within a community to cease their deforestation activities or, in cases where deforestation pressures come from outside the communities, to increase conservation activities like forest monitoring for encroachment. These changes must either come through an income effect that is large enough to remove the need to extract goods from the forest, or through a price effect in the form of a transfer-be it in cash or kind-conditional on ceasing extraction or participating in conservation. The PES program belongs in the category of a conditional cash transfer (CCT) that creates a price effect on forest conservation. Per unit of payment received, a CCT should have a larger incentive effect on forest conservation than a non-conditional payment would have. ${ }^{4}$

\subsubsection{Give Voice to Water Service Providers}

One final political lesson is to allow water service providers to participate in the design and management of the program. Although bureaucratic limitations did not allow CONAFOR to funnel the payments through the municipalities, the early participation of the water service providers could have worked in several ways to bolster the success of the program. First, because they know their localities, these service providers could have helped to target properties, which were particularly important for the provision of water. There is a general sense among water providers in Mexico that problems with water supply are simply normal seasonal or yearly fluctuations, which are not directly linked with overall management of the watershed. Where water providers are concerned about this link, as is the case in southern Veracruz and some states in Northern Mexico, this awareness was triggered by severe drought years and crippling water shortages. This knowledge is absolutely essential for the development of markets for hydrological services, which is the final goal of the program. Water service providers are an important link in the accountability circle. They can generate awareness among consumers of water, who can then pressure policymakers either directly or indirectly. The providers themselves are directly linked with the government because they are either municipalities or private providers operating under the supervision of municipal authorities who are in communication with the government. They are, therefore, in a position to demand results from the program-increasing the

${ }^{4}$ See by analogy the discussion on incentive effects from cash transfers vs. CCT for education under Progresa (de Janvry \& Sadoulet, 2006). 
accountability of the environmental service providers, and helping provide another source of pressure on policymakers to continue allocating a budget for the program.

\subsubsection{Financing Lessons}

\subsubsection{Sustainability of the Funding Source}

As was described above, the current financing from the program, consisting in an annual budget of $\$ 20$ million, has been approved by Congress. This does probably not qualify as a sustainable financial arrangement since, though it has been written into law, it is decoupled from the intentions of the program and subject to the political process. The Mexican program is seeking sustainability through the development of local markets for environmental services, a criterion that led to the selection of ejidos with downstream populations of over 5,000. As we saw in the section describing the current participants in the program, the distribution of the enrolled hectares is widely dispersed-in 2003, the program enrolled 271 properties in 15 states. The small number of participants per large population area may make it difficult to establish markets for two reasons. First, there may not be a sufficient number of hectares enrolled to actually make a substantial impact on the downstream water quality and quantity. Second, dispersion of the participants may make it costly to organize such markets. Although the development of markets would be sustainable as long as demand for environmental services is strong, it is currently unclear how the transition from subsidy to market will occur.

In some Mexican cities, with Coatepec in Veracruz serving as an outstanding example, markets for environmental services have developed in the absence of the payment program (though the program has been used to support Coatepec in the past two years). It is important to note, however, that initiation of the program in Coatepec followed a water crisis in the city, which raised the local demand for water services from forests in the mountains above the city.

\subsubsection{Mechanisms to Guarantee Long-Term Contracts}

Despite the potential tenuousness of the program's budget, we do extract one very positive lesson from the financing of Mexico's program: the usefulness of creating a trust fund which guarantees the ability to provide payments to recipient communities over an extended period. For environmental services programs to be taken seriously, funding must be guaranteed over a substantial period of time. The FFM is a clever mechanism that circumvents the political budgeting process by allowing money allocated in one year to be used in subsequent years. This security, 
however, comes at the cost of a substantial part of the budgeting money sitting idle each year. In the case of the FFM, as each year's new budget comes in, fourfifths of it is put into the fund, where it is paid in equal installments over the next four years. If one could rely on the yearly financing of the scheme, considerably more hectares could be enrolled in the first five years of the process than are actually in it. However, in the face of insecure political outcomes, the trust fund mechanism plays an important role in enabling long-term contracts with service providers in spite of reliance on politically uncertain annual budget appropriations.

\subsubsection{Use Bankable Certificates}

An alternative to the FFM approach is to use the strategy undertaken by PROCAMPO, an agricultural subsidy program introduced in 1994 to compensate farmers for the negative price effects of NAFTA. Under PROCAMPO, farmers are given payment certificates against which they can borrow money from the bank. Using such a strategy would allow for all of the money granted by Congress each year to be used to pay communities. Had such an approach been taken, CONAFOR would have been able to contract five times as many hectares in 2003. The key to making such a system work is a guarantee of funding from the federal budget for the length of the contracts, in this case, five years.

\subsubsection{Targeting Lessons}

\subsubsection{Target Public Goods Important within National Boundaries}

Mexico was wise in its choice of hydrological services provided by forests as the focus of the program. Because the water quality and quantity associated with forests is a good that is solely consumed within watersheds, almost all of which are entirely within national boundaries, it was much easier to seek financing from Congress and to look towards the development of local markets. Despite the fact that the targeting of the payments was skewed by the choice of the implementing agency (see section 10.5.1.2), the current targeting scheme is moving towards achieving the goals of the program, with big improvements in the 2004 implementation, where communities located in priority watersheds are given preference. It is also a scheme that would be simple to apply in various contexts, although it does require having sufficient information to prioritize the watersheds that are key to preserve the environmental service of concern.

\subsubsection{Take into Account Risk of Service Loss}


The most efficient way of allocating payments in environmental programs is to pay the lowest cost possible for those hectares of land containing benefits that are at risk of being lost. If the risk of service loss (in this case, deforestation) is not taken into account, then large amounts of money will be spent paying for environmental services that were never at risk of being lost in the first place. Our summary statistics on program participants in Mexico (see section 10.4.1.) showed that a large number of hectares enrolled (72\% in 2003 and 52\% in 2004) had either low or very low risk of deforestation. This implies that the current targeting strategy is inefficient. The efficiency of the current scheme could be enormously improved by taking into account both the risk of losing these benefits and the cost of conserving them. In a 2004 paper simulating the effects of different payment targeting schemes to ejidos in Mexico, Alix-García et al. (2008) showed that for the same budget, payments allocated to maximize expected benefits per dollar lead to a fourfold increase in efficiency over a scheme analogous to the current one which offers a flat payment per hectare with a cap on the number of allowable hectares.

Operationalizing this scheme means developing some measure of environmental benefits, weighting these benefits by the deforestation risk, and creating a ratio of expected benefits to opportunity cost that allows the ordering of properties. One then begins to pay those with the highest expected benefit/cost ratio and proceeds down the line until the budget is exhausted. Clearly, the three elements necessary to implement this scheme are: (1) some measure of the environmental benefits offered by land in each ejido, (2) a measure of the opportunity cost per hectare, and (3) an estimate of the risk of forest loss. It would be possible to implement this approach by using a bidding process (as suggested above) to reveal the opportunity cost of hectares in forest, and then use the ratio of the expected environmental benefits to the bid made as the targeting criterion.

Payments in the second round of the program begin to fill one of the criteria of a targeting strategy that maximizes environmental benefits per dollar, that is to say, payments are broadly allocated to regions where water resources are overutilized. They are, therefore, directed towards communities where the environmental benefits are relatively higher. Another related lesson is that, in general, where forestry projects are very profitable, forests will be conserved because it is in the interest of the owners of this forest that it keeps supplying lumber over the long term. Payments should therefore be directed away from these communities towards those with unprofitable forestry projects or to non-commercial forests.

\section{Concluding Remarks}

We began this chapter with an overview of the state of the Mexican forest, whose considerable riches are at risk of being lost due to a combination of perverse incentives, one of which is the lack of a market for the environmental services that it provides. This forest is a prime example of a natural resource which supplies 
services in addition to its extractive value; it sequesters carbon dioxide, shelters biodiversity, prevents erosion, provides a destination for local and international tourists, and plays an important role in regulating a complex hydrological system. Mexico chose to pay for hydrological services through a PES program. The possibilities and pitfalls of this experience have taught us lessons that will both help improve the Mexican program and assist in designing PES programs for other services and in other countries.

Our analysis showed that payments as they were distributed in 2003 and 2004 did not necessarily achieve the goals of the program - they were largely allocated to hectares of land that were not within critical watersheds. They are also so fragmented in their distribution that they are unlikely to be providing measurable services to downstream water providers. In addition, they were not targeted at forests that were at risk of being lost. Our case studies showed that there was little pressure to deforest in the communities chosen to receive payments and that, as a result, there were very few behavioral changes induced by the program payments. In some cases, however, the payments did serve to increase participation in conservation activities. One serendipitous effect of the targeting was that the majority of payments went to poor and very poor forest-holders.

The sources of this bias in the program are various, many of them stemming from factors beyond the program designer's control. One of the most important was the choice of service provider, CONAFOR, whose objectives were not directly aligned with those of the proposed policy. The trade-off in this choice, however, was a large one. CONAFOR was very successful in lobbying for a budget for the program and in ensuring that its first phase was implemented within a very restrictive political timetable. Other important factors that affected and will continue to affect the program's success are related to accountability. Without awareness on the part of water providers and consumers, accountability of forestholders to provide environmental services will be very limited, and it is unlikely that local markets for hydrological services will emerge. In addition, without pressure from these groups, it will become increasingly difficult for the program to continue to receive budgetary support from Congress. There are also problems of accountability within communities - if the program continues to be misunderstood by recipients, the contracts are likely to be broken and market formation hindered.

The program in Mexico is still quite young, and will surely have many future lessons to teach us. A thorough evaluation of the actual impact of the program on forest cover will eventually need to be done, and this will require considerable GIS work as well as further surveying of the participant (and some nonparticipating) communities. In addition, the question of the optimal design of payment contracts in the context of forest common properties has yet to be answered.

Furthermore, we do not know whether the payment level that is currently being used is appropriately set. It is clear that the payment level was high enough to attract a substantial number of participants, but it would seem that often those who chose to participate had no intention of cutting down the forest in the first place. 
As we saw in the case studies, some communities showed absolutely no change in behavior upon receiving program payments. Part of this may have been because the overall payment amounts were not very high; they could probably have been lower with the same result. Calibration of the payments must take into account the fact that forests at higher risk of deforestation, i.e., with a greater opportunity cost, will require larger payments. The logical conclusion is that payments must be differentiated according to the level of risk associated with a given forest. The design of such a differentiated scheme, however, requires considerably more research.

Finally, recalling that the goal of the program is to develop markets for environmental services within Mexico, an essential part of future research should include a rigorous assessment of where these markets can truly be developed. This requires knowing which forests are essential to which watersheds, if they are at risk or not, and the quality and quantity of the demand for services by downstream users. Integral to such an analysis is identifying forests that could be preserved through means other than environmental services payments - i.e., through changes in the incentive structure created by forest policy. The portrait of forests at risk could then be completed by those that cannot be saved by markets or through changes in forest policy. It is these that will require either mandated protection or continuous payments from federal or international funding sources.

Acknowledgments This document is based upon a report prepared for Randy Stringer at the Comparative Studies Service Agricultural and Development Economics Division, United Nations Food and Agriculture Organization (FAO). The work was coordinated by Alain de Janvry and Elisabeth Sadoulet, professors at the Department of Agricultural and Resource Economics, University of California at Berkeley. The Political Economy Section is largely based on the contribution by Josefina Braña Varela and Maria Zorilla Ramos. Fieldwork for the study cases was coordinated by Jaime Sainz, Adán Martínez, and Josefina Braña.

\section{References}

Alix-Garcia J, de Janvry A, Sadoulet E (2008) The role of deforestation risk and flexible compensation in designing payments for environmental services, Environ Dev Econ, forthcoming

Central Intelligence Agency (CIA) (2005) World Fact Book 2004 Online http://www.cia.gov/ cia/publications/factbook/fields/2004.html

CONAFOR (2001) Comisión Nacional Forestal, Semarnat Programa Nacional Forestal 20012006

Colegio de Posgrados (COLPOS) (2004) Valuación de Programa de Pago por Servicios Ambientales Hidrológicos Working Paper

CONAPO (2000) Indices de Marginación, 2000. Mexico City, Mexico

de Janvry A, Sadoulet E (2006) Making conditional cash transfer programs more efficient: Designing for maximum effect of the conditionality. World Bank Econ Rev 20:1-29

García Coll I (2002) Potencial de recarga de acuíferos y estabilización de ciclos hídricos de areas forestadas. Reporte de Investigación. México: INE-DGIPEA (processed)

INE, Instituto Nacional de Ecología (2004) "Encuesta de los ejidos participantes en el programa de PSAH" Survey of ejido participants in the PSA-H. 
Mayrand K, Paquin, M (2004) Payments for environmental services: A survey and assessment of current schemes. Unisfera International Center (for the Commission for Environmental Cooperation of North America) http://www.cec.org/files/PDF/ECONOMY/PESUnisfera_en.pdf

Muñoz C, Guevara A, Bulás JM, Torres JM, Braña J (2005) Pagar por los servicios hidrológicos del bosque en México. Draft Book Chapter.

National Forest Inventory (2000) SEMARNAT - Secretariat of Environment and Natural Resources

Nature Conservancy (2003) home page: www.nature.org

SEMARNAT (2004) La experiencia de México en el pago por servicios ambientales hidrológicos y el fondo forestal Mexicano. Powerpoint presentation.

Velázquez A, Mas J, Palacio J (2003) Análisis del cambio de uso del suelo Convenio INE-IGg (UNAM) (Oficio de autorización de inversión 312.A.-00215), Instituto de Geografía, UNAM, Enero

World Bank (2005) Current World Bank work on payments for ecological services. http://nweb18.worldbank.org/ESSD/envext.nsf/44ByDocName/PaymentsforEcologicalServi cesCurrentProjects

Wu J (2000) Slippage effects of the conservation reserve program. Am J Agric Econ 82(4):97992 